\title{
Matrix Metalloproteinase-28 Is a Key Contributor to Emphysema Pathogenesis
}

Anne M. Manicone, ${ }^{*}$ Sina A. Gharib, ${ }^{*}$ Ke-Qin Gong, ${ }^{*}$ William E. Eddy, ${ }^{*}$ Matthew E. Long, ${ }^{*}$ Charles W. Frevert, ${ }^{* \dagger}$ William A. Altemeier, ${ }^{*}$ William C. Parks, ${ }^{\ddagger}$ and A. McGarry Houghton ${ }^{\star \S}$

From the Departments of Medicine* and Comparative Medicine, ${ }^{\dagger}$ Center for Lung Biology, University of Washington, Seattle, Washington; the Women's Guild Lung Institute, ${ }^{\ddagger}$ Cedars-Sinai Medical Center, Los Angeles, California; and the Divisions of Clinical Research and Human Biology, ${ }^{\S}$ Fred Hutchinson Cancer Research Center, Seattle, Washington

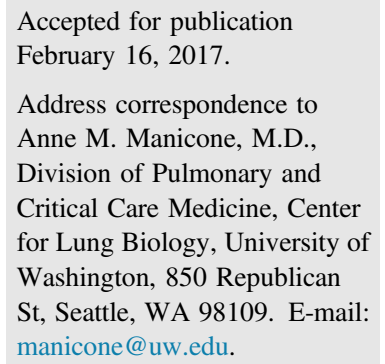

Chronic obstructive pulmonary disease (COPD) comprises chronic bronchitis and emphysema, and is a leading cause of morbidity and mortality. Because tissue destruction is the prominent characteristic of emphysema, extracellular proteinases, particularly those with elastolytic ability, are often considered to be key drivers in this disease. Several human and mouse studies have implicated roles for matrix metalloproteinases (MMPs), particularly macrophage-derived proteinases, in COPD pathogenesis. MMP-28 is expressed by the pulmonary epithelium and macrophage, and we have found that it regulates macrophage recruitment and polarization. We hypothesized that MMP-28 has contributory roles in emphysema via alteration of macrophage numbers and activation. Because of the established association of emphysema pathogenesis to macrophage influx, we evaluated the inflammatory changes and lung histology of $M m p 28^{-/-}$mice exposed to 3 and 6 months of cigarette smoke. At earlier time points, we found altered macrophage polarization in the smoke-exposed $M m p 28^{-/-}$lung consistent with other published findings that MMP-28 regulates macrophage activation. At both 3 and 6 months, $M m p 28^{-/-}$mice had blunted inflammatory responses more closely resembling nonsmoked mice, with a reduction in neutrophil recruitment and CXCL1 chemokine expression. By 6 months, Mmp28 ${ }^{-1-}$ mice were protected from emphysema. These results highlight a previously unrecognized role for MMP-28 in promoting chronic lung inflammation and tissue remodeling induced by cigarette smoke and highlight another potential target to modulate COPD. (Am J Pathol 2017, 187: 1288-1300; http://dx.doi.org/ 10.1016/j.ajpath.2017.02.008)
Chronic obstructive pulmonary disease (COPD) comprises chronic bronchitis and emphysema, and is a leading cause of morbidity and mortality worldwide. With more than two million individuals dying annually of COPD, efforts to understand disease pathogenesis are paramount. Cigarette smoking is the leading cause of COPD, with air pollution also being a contributor. ${ }^{1-3}$ Because destruction of alveolar tissue and extracellular matrix is the prominent characteristic of emphysema, ${ }^{2,4-6}$ extracellular proteinases, particularly those with elastolytic ability, are often considered to be key drivers in COPD. ${ }^{2,7-10}$ Several human and mouse studies have implicated roles for various matrix metalloproteinases (MMPs), particularly macrophage-derived proteinases, in COPD pathogenesis. ${ }^{3,9,11-21}$ Increased macrophage numbers are associated with COPD, and emphysema develops coincident with increased macrophage influx in several mouse models. ${ }^{13,22-26}$ Hence, factors that inhibit macrophage recruitment and activation could alter the pathobiology of COPD and represent an important area to study.

Mammalian MMPs comprise a family of 24 to 25 endopeptidases that act on numerous, diverse extracellular substrates. Many MMPs, with MMP-28 being a key exception, are not expressed in normal tissue; however, they are produced by most cell types in essentially all repair,

Supported by NIH grants R01 HL116514 (A.M.M.), P30-ES-007033-196363 (A.M.M.), and P30 DK089507 (C.W.F.)., and the Early Physician Scientist Award from Howard Hughes Medical Research Institute (A.M.M.). Disclosures: None declared. 
inflammatory, and disease settings. ${ }^{27,28}$ MMP-28 (epilysin) is the last identified member of the MMP family. It has the prototypic domains of an MMP, and it also contains a furin activation sequence and is activated within the secretion pathway. ${ }^{29-31}$ We and others have demonstrated that MMP28 localizes to the plasma membrane of cells, thereby spatially confining its activity. ${ }^{32,33}$ In both murine and human tissues, Mmp28/MMP28 mRNAs are constitutively expressed at high levels, particularly in the lung. ${ }^{29}$ In murine lung, we demonstrated that MMP-28 is expressed by Club cells and promotes epithelial cell survival. ${ }^{32}$ We also identified its expression by monocytes and macrophages and have shown that MMP-28 restrains macrophage recruitment to tissue and modulates macrophage polarization, promoting a less inflammatory, more reparative phenotype associated with impaired tissue fibrosis in $\mathrm{Mmp} 28^{-/-}$mice. ${ }^{34-36}$

Because of the established association of emphysema pathogenesis to macrophage influx, we evaluated the inflammatory changes and lung histology of $\mathrm{Mmp} 28^{-/-}$ mice exposed to 3 and 6 months of cigarette smoke. After 6 months of smoke exposure, Mmp $28^{-/-}$mice were protected from emphysema and had a marked reduction in inflammation. At earlier time points, $M m p 28^{-/-}$mice had blunted inflammatory responses more closely resembling nonsmoked mice, with a reduction in neutrophil recruitment and CXCL1 chemokine expression. In addition, macrophage gene expression was altered in $M m p 28^{-/}$consistent with other published findings that MMP-28 regulates macrophage polarization. Overall, these results highlight a previously unrecognized role for MMP-28 in emphysema.

\section{Materials and Methods}

Animals

Age- and sex-matched C57BL/6 and $\mathrm{Mmp}^{28^{-/-}}$(on a C57BL/6 background) mice were used for all experiments. At 7 to 9 weeks, mice were exposed to cigarette smoke from University of Kentucky 3R4F Reference Brand cigarettes using a JB-2082 cigarette smoke machine (CH Technologies, Westwood, NJ). Mice were exposed to cigarette smoke in large rodent cages in groups of $N=10$. The smoke exposures were 3 hours in duration for 5 days per week at a concentration of 250 total particulate matter $/ \mathrm{m}^{3}$ for a total of 3 or 6 months. Controls were kept in the same facility and exposed to room air within a similar chamber. The Fred Hutchinson Research Center and the University of Washington Office of Animal Welfare approved all animal protocols.

\section{Morphometry}

After euthanasia, the lungs were inflated ex vivo with $10 \%$ buffered formalin at $25 \mathrm{~cm} \mathrm{H}_{2} \mathrm{O}$ pressure for 10 minutes using an intratracheal catheter. Gill's stained serial midsagittal formalin-fixed, paraffin-embedded sections were subjected to morphological analysis, as previously described. ${ }^{37}$ Ten randomly selected $\times 20$ fields per slide were imaged using Nikon Elements version 4.0 (Nikon, Melville, NY). The images were analyzed using Scion Image version 2.2 (Scion Corp., Frederick, MD). Airway, vascular, and immune cell structures were eliminated from the analysis. Results are expressed as chord length, in $\mu \mathrm{m}$, or as alveolar tissue area, as determined using MetaMorph (Molecular Devices, Sunnyvale, CA).

\section{Blood Collection}

In naïve mice, blood was collected via cardiac puncture and anticoagulated using 4\% EDTA (Fisher Scientific, Hanover Park, IL). An equal volume of blood per mouse $(400 \mu \mathrm{L})$ was lysed using red blood cell lysis buffer, per manufacturer's protocol (eBioscience, San Diego, CA). This lysis protocol was repeated to remove remaining erythrocytes. After red blood cell lysis, pelleted cells were resuspended in an equal volume of fluorescence-activated cell sorting (FACS) buffer [phosphate-buffered saline (PBS), 0.5\% EDTA].

\section{BAL}

In some mice, the trachea was cannulated with an angiocatheter. Bronchoalveolar lavage (BAL) was performed with three serial instillations of lavage buffer (PBS, 0.5\% EDTA) (total volume, $2.5 \mathrm{~mL}$ ). BAL cells were pelleted and resuspended in RPMI $1640+10 \%$ fetal bovine serum, and approximately 50,000 cells placed on slides using a cytospin. Cells were stained with Differential quik (VWR, Radnor, PA), and a manual differential was performed on 100 cells. In separate experiments, BAL cells were resuspended in FACS buffer and processed for FACS.

\section{Lung Tissue Processing}

To isolate pulmonary leukocytes from naïve mice, the pulmonary vasculature was perfused with $10 \mathrm{~mL}$ cold PBS after blood collection via cardiac puncture. The perfused, nonlavaged lungs were then dissociated mechanically with scissors and incubated with $1 \mathrm{mg} / \mathrm{mL}$ Liberase TM (Roche, Indianapolis, IN) and $1 \mathrm{mg} / \mathrm{mL}$ DNAase I (Sigma Aldrich, St. Louis, MO) for 10 minutes at $37^{\circ} \mathrm{C}$. Lung digests were filtered through a 70- $\mu \mathrm{m}$ nylon cell strainer (Becton Dickinson, Franklin Lakes, NJ), and erythrocytes were removed using red blood cell lysis buffer. Cells were resuspended in FACS buffer.

\section{Cell Processing for FACS}

Blood, BAL, and lung cells were counted using an automated cell counter (Nexcelcom Bioscience, Lawrence, MA). Cells were incubated with Fc block (antimouse CD16/ CD32; eBioscience) in $100 \mu \mathrm{L}$ of FACS buffer (PBS, 0.5\% 
EDTA) followed by the antibody panels below. Labeled cells were analyzed using BD FACSCanto RUO (BD Biosciences, San Jose, CA) and the FlowJo data analysis software version X 10.0.7r2 (Ashland, OR). Antibodies used included the following: antimouse CD62L-APC, ICAM1FITC, Ly6G-FITC, Ly6G-PerCP/Cy5.5, LFA-1-PE, CD45APC/Cy7， CD4-PE， CD8-PB， CXCR2-PerCP/Cy5.5, Gr1-PB, Ly6C-PB (BioLegend, San Diego, CA), CD11CAPC, CD11b-PECy7, CD3e PE/Cy7, CD3e-PerCP/Cy5.5, CD71-PE, F4/80-APC (eBioscience).

\section{Quantitative RT-PCR}

Total RNA from cells was isolated using RNeasy Mini kit (Qiagen, Valencia, CA). The quantity and quality of RNA were determined using a NanoDrop spectrophotometer (NanoDrop Inc., Wilmington, DE). Primers and TaqMan probes (FAM dye labeled) for Mmp9, Mmp12, Mmp28, Cxcll, and Hprt were added to cDNA synthesized from total RNA with a High-Capacity cDNA Archive kit (Applied Biosystems, Carlsbad, CA). Product amplification was measured with an ABI HT7900 Fast real-time PCR system (Applied Biosystems). The $\mathrm{C}_{\mathrm{T}}$ was obtained from duplicate samples and averaged. The $\Delta C_{T}$ was the difference between the average $\mathrm{C}_{\mathrm{T}}$ for the target gene and the housekeeping gene, Hprt. The $\Delta \Delta \mathrm{C}_{\mathrm{T}}$ was the average $\Delta \mathrm{C}_{\mathrm{T}}$ for a given sample point minus the average $\Delta \mathrm{C}_{\mathrm{T}}$ of control samples. The data are expressed as relative quantification calculated as $2^{-\Delta \Delta C_{T}}$.

\section{Immunohistochemistry}

Lung tissue from COPD and non-COPD patients was obtained using the Northwest Biorepository (Seattle, WA). Smoking history was also provided by the Biorepository. All of the COPD patients were former smokers with cessation of smoking ranging from 6 months to 21 years before tissue collection. None were active smokers; one reported current smokeless tobacco use. Among the nonCOPD group, none were active smokers. Lung tissue had been fixed in $10 \%$ formalin and paraffin embedded. Lung sections were deparaffinized in HistoClear (National Diagnostics, Atlanta, GA) and rehydrated through graded ethanol. Antigen retrieval was performed using antigen retrieval solution, HIER1 (citrate) heated to $100^{\circ} \mathrm{C}$ for 10 minutes. Normal goat serum (10\% in tris-buffered saline) was applied to each section for 20 minutes. Sections were incubated with antihuman MMP-28, 1:250 (Proteintech) or RabIgG in Leica primary antibody diluent for 30 minutes at room temperature, and secondary antibody for 1 hour at ambient temperature. After each incubation, the sections were washed three times in PBS. Secondary antibodies were labeled with the Leica Bond Polymer diaminobenzidine refine for 8 minutes at room temperature and the Leica bond mixed refine (diaminobenzidine) detection per the manufacturer's protocol. Tissue was counterstained with hematoxylin. Slides were scanned in brightfield with a $20 \times$ objective using a NanoZoomer Digital Pathology System (Hamamatsu City, Japan). The digital images were then imported into Visiopharm software version 6.7.0.2590 (Hoersholm, Denmark) for analysis. Using the Visiopharm Image Analysis module, a region of interest was manually drawn around the lung sections to select for alveolar tissue. The software was then trained to detect positive staining, MMP-28, and the background tissue counterstain, hematoxylin, using a project-specific configuration base on a threshold of pixel values. The images were processed in batch mode using this configuration to generate the desired per area outputs. For murine samples, polymorphonuclear leukocyte (PMN) staining was performed using $0.1 \mu \mathrm{g} / \mathrm{mL}$ antimurine Ly-6B.2 antibody (Bio-Rad Laboratories, Raleigh, NC) or IgG2a control in a similar protocol as above. PMNs were manually counted over a given area and averaged over 10 random fields.

\section{Cytokine Measurements}

Cytokine and chemokine concentrations for CXCL1/KC, CXCL2/macrophage inflammatory protein (MIP)-2 $\alpha$, and CXCL5/LIX were measured in BAL samples using a magnetic bead Luminex assay, per manufacturer instructions (R\&D Systems, Minneapolis, MN) and analyzed on Bioplex 200 (Bio-Rad Laboratories, Raleigh, NC).

\section{Microarray Experiments and Analysis}

Total RNA from whole lungs was isolated using RNeasy Mini kit, its integrity confirmed using an Agilent 2100 Bioanalyzer (Agilent Technologies, Inc., Santa Clara, CA), converted to cDNA, biotin labeled, and then hybridized to Illumina Mouse Ref-8 version 2 Expression BeadChips (Illumina, Inc., San Diego, CA). After image processing using an Illumina iScan system, microarray data were background adjusted (based on microarray control probe expression) and normalized (variance-stabilizing transformation) using the Bioconductor package lumi. For each genotype [wild type (WT), Mmp2 $8^{-1-}$ ], differentially expressed genes in response to 3 months of cigarette smoke exposure were identified using a Bayesian implementation of the $t$-test applied to log-transformed intensities. ${ }^{38} \mathrm{Ben}$ jamini-Hochberg's false discovery rate (FDR) method for multiple testing correction was applied to $P$ values, ${ }^{39}$ and an FDR $<0.01$ was used for significant differential gene expression. To identify genes altered exclusively in one genotype in response to smoke exposure, we required significant differential expression in that genotype (FDR $<0.01)$ and absence of change in the other genotype (FDR > 0.1). Functional enrichment analysis of differentially expressed genes was performed using Webgestalt software version 2013, ${ }^{40}$ and was based on Gene Ontology $^{41}$ and Mammalian Phenotype Ontology ${ }^{42}$ databases. Relative enrichment to mouse genome (based on a 

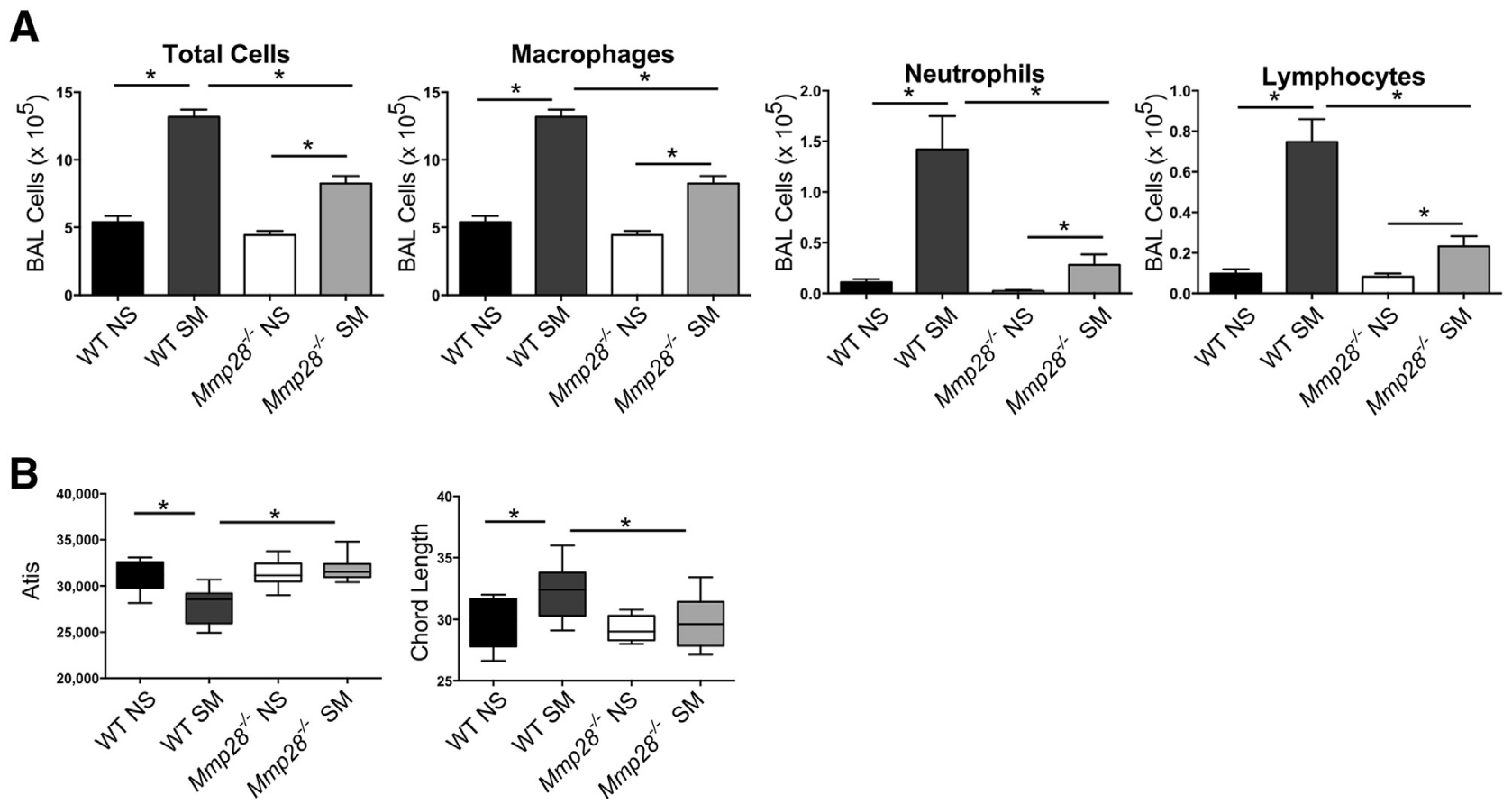

C
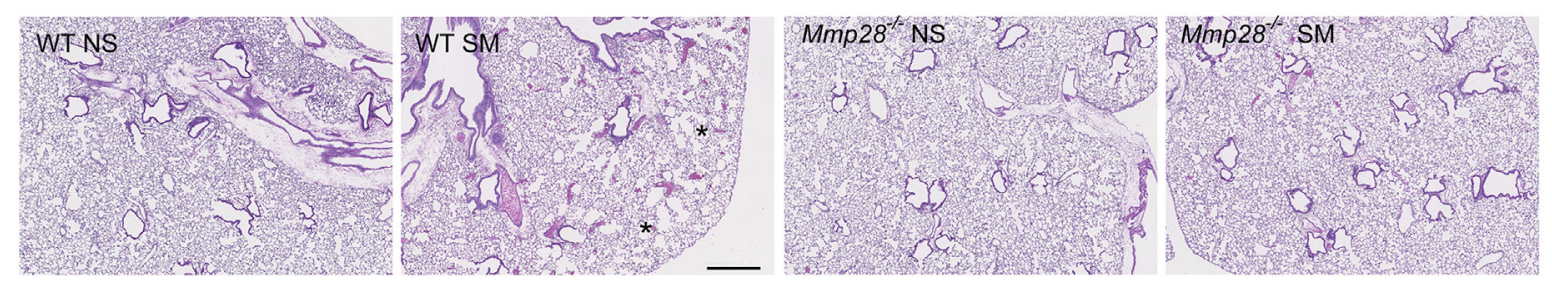

Figure 1 Mmp28 is required for chronic inflammatory changes to cigarette smoke exposure at 6 months. After 6 months of cigarette smoke exposure (SM) or room air control (NS), wild-type (WT) and $M m p 28^{-1-}$ mouse lungs were lavaged, and the bronchoalveolar lavage (BAL) leukocyte populations analyzed by cytospin. A: In SM mice compared to NS controls matched by genotype, there is a significant increase in total alveolar macrophages, neutrophils, and lymphocytes in response to cigarette smoke exposure. However, the absence of Mmp28 is associated with significantly smaller smoke-induced increases in macrophages (0.7-fold of WT SM), neutrophils (0.2-fold of WT SM), and lymphocytes (0.3-fold of WT SM) in the alveolar compartment. B: Alveolar tissue area (Atis) and mean chord length (CL) were quantified, and Atis decreases and CL increases in WT SM versus NS but not in Mmp28 ${ }^{-/-}$SM mice. C: Representative histology (hematoxylin and eosin staining) of WT SM and $M m p 28^{-1-}$ SM compared to room air controls demonstrating mild emphysematous changes in WT SM mice (asterisks indicate enlarged alveoli). $n=10$ mice per genotype per group (A-C). ${ }^{*} P<0.05$. Scale bar $=500 \mu \mathrm{m}(\mathbf{C})$.

background of all transcripts in the Illumina Mouse Ref-8 version 2 BeadChip) was calculated using the hypergeometric test, and multiple testing correction of $P$ values was performed using Benjamini-Hochberg's method. Only processes with adjusted enrichment $P$ values $<0.01$ were deemed significant. The microarray data have been submitted to the NIH Gene Expression Omnibus (https://www. ncbi.nlm.nih.gov/geo; accession number GSE93898).

\section{Neutrophil Isolation and Assessments}

Age- and sex-matched 8- to 12-week-old WT and Mmp28 $8^{-/}$ mice were used to isolate bone marrow neutrophils using $62 \%$ Percoll-Hanks' balanced salt solution (Percoll GE Healthcare, Uppsala, Sweden) gradient. The purity of neutrophils was assessed by cytospins, and $>90 \%$ of cells were PMNs. Cells were enumerated using an automated cell counter (Nexcelom Bioscience, Lawrence, MA), and $1 \times 10^{6}$ cells plated. In some conditions, cells were treated with $100 \mathrm{ng} / \mathrm{mL}$ phorbol myristate acetate (Sigma, St. Louis, MO) for 4 to 24 hours. At 4 and 24 hours, cells were centrifuged and the supernatant used to measure myeloperoxidase activity using 3,3,5,5'-tetramethylbenzidine substrate solution, per manufacturer's protocol (Cayman, Ann Arbor, MI). Myeloperoxidase activity was reported as $\Delta \mathrm{A} 650 / 60$ minutes. To measure neutrophil elastase activity, cells were treated with lysis buffer (Cell Signaling Technology, Danvers, MA), and AAPV-pVA $2 \mathrm{mmol} / \mathrm{L}$ (Sigma) in Tris-NaCl buffer used to measure neutrophil elastase activity, per manufacturer's protocol. Neutrophil elastase activity was reported as $\Delta \mathrm{A} 410 / 60$ minutes.

\section{Statistical Analysis}

Results are expressed as means \pm SEM. Statistical significance was determined using $t$-test. Differences were considered significant if the $P$ value was $<0.05$. 
A

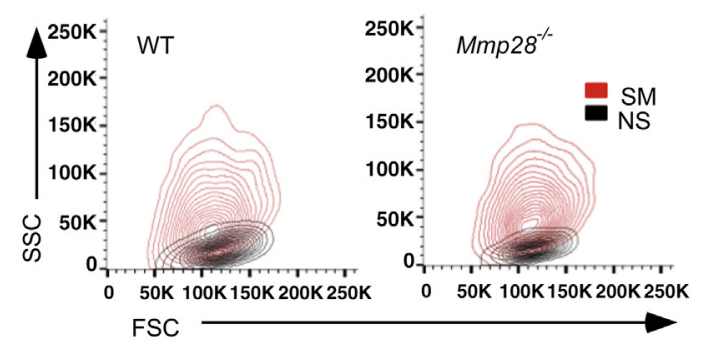

B

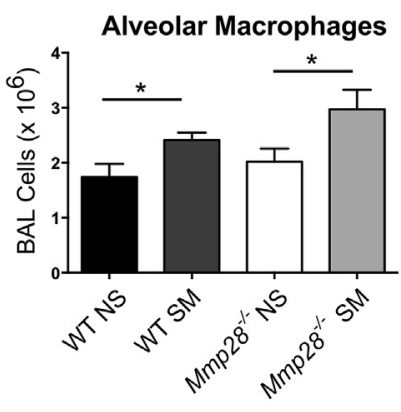

C
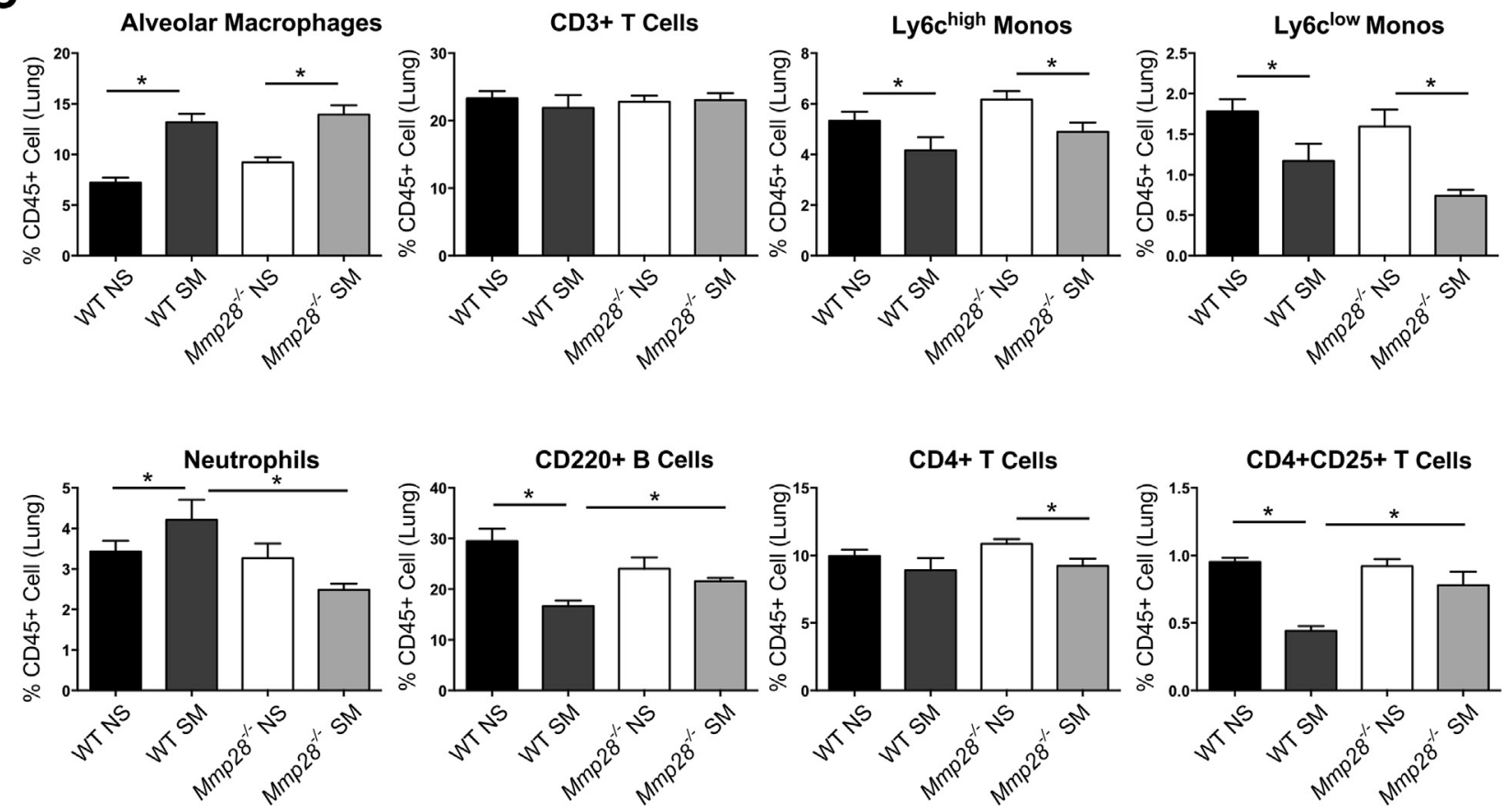

E
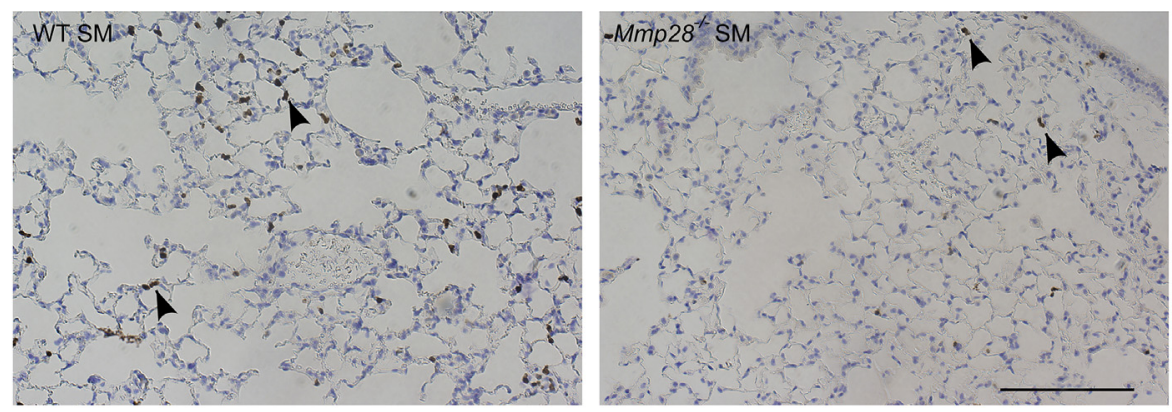

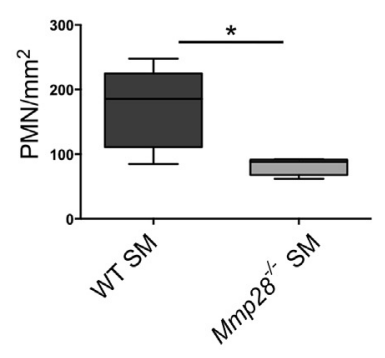

Figure 2 Mmp28 deficiency alters lung inflammation in chronic tobacco smoke exposure. After 3 months of chronic tobacco smoke exposure (SM) or room air control (NS), wild-type (WT) and Mmp28 ${ }^{-/-}$mouse lungs were lavaged and dissociated. The bronchoalveolar lavage (BAL) leukocyte populations (A and B) and lung leukocytes (C) were analyzed using FACS. A: In smoke-exposed mice, there is a significant increase in alveolar macrophage size [forward scatter (FSC)] and granularity [side scatter (SSC)] in both genotypes. B: In SM WT and Mmp28 ${ }^{-1-}$ mice, there are more alveolar macrophages compared to NS controls. C: In WT SM mice compared to WT NS control lung digests, there is an increase in alveolar macrophages and neutrophils (as percentage of CD45 ${ }^{+}$

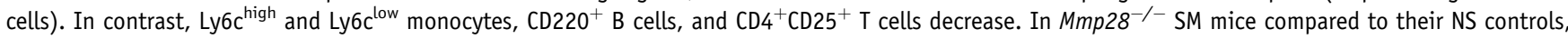
there is an increase in alveolar macrophages, but no change in neutrophils, B cells, and $\mathrm{CD}_{4}^{+} \mathrm{CD} 25^{+} \mathrm{T}$ cells. Overall, with the exception of alveolar macrophages, the absence of Mmp28 in smoke-exposed mice is associated with fewer inflammatory changes. D and E: Polymorphonuclear leukocyte (PMN) localization and quantification using immunohistochemistry for Ly6b in WT SM and Mmp28 ${ }^{-/}$SM lungs demonstrating reduced PMNs in Mmp28-/- SM lungs, the majority residing within or along the alveolar wall (arrowheads). $n=5$ mice per genotype per group (A-E). ${ }^{\star} P<0.05$ (two to three experimental replicates). Scale bar $=100 \mu \mathrm{m}$ (D). 

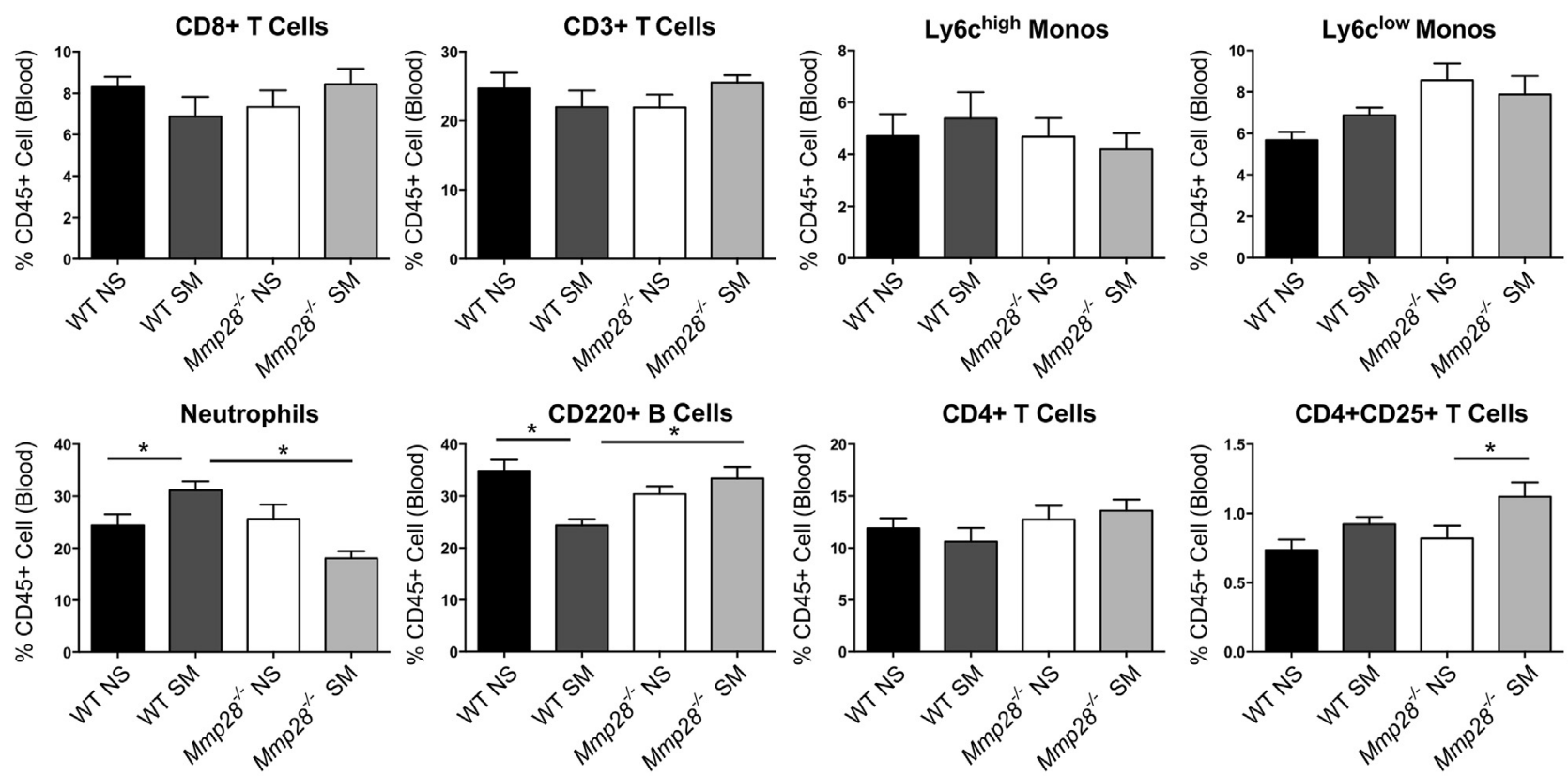

Figure 3 Changes in circulating leukocytes in chronic tobacco smoke exposure. After 3 months of chronic tobacco smoke exposure (SM) or room air control (NS), wild-type (WT) and Mmp28 ${ }^{-1-}$ mice had their blood collected via cardiac puncture. The leukocyte populations were evaluated using FACS. Overall, the leukocyte differential is similar between NS mice of either genotype. In WT SM mice, there is an increase in neutrophils and a decrease in B cells (as percentage of CD45 cells) compared to their NS control. These changes are not observed in the Mmp28 ${ }^{-1}$ SM mice. $n=2$ experimental replicates; $n=5$ mice per genotype per group. ${ }^{*} P<0.05$.

\section{Results}

\section{Chronic Pulmonary Inflammation and Emphysema} Induced by Tobacco Smoke Exposure Requires MMP-28

C57B1/6 WT and Mmp28 $8^{-/-}$mice were exposed to chronic tobacco smoke (SM) 5 days/week for 6 months or room air control (NS). At the end of this time point, the lungs were evaluated for inflammatory cell influx into the alveolar compartment by cell counts and differential. The lungs were inflated and processed for evaluation by hematoxylin and eosin and Giemsa staining. At 6 months, WT SM mice had a significant increase in alveolar macrophages, neutrophils, and lymphocytes (Figure 1A). Compared to WT SM mice, Mmp28 $8^{-/-}$SM mice had a blunted inflammatory response, particularly involving PMNs (fivefold less than WT) and lymphocytes (3.2-fold less than WT). In Mmp28 ${ }^{-1-}$ SM mice, macrophage influx was 1.4-fold less than that of WT. These findings indicate that MMP-28 is critical for leukocyte recruitment into chronic smoke-exposed lungs.

We also assessed the lungs for alveolar tissue area and mean chord length, a measure of emphysematous
A

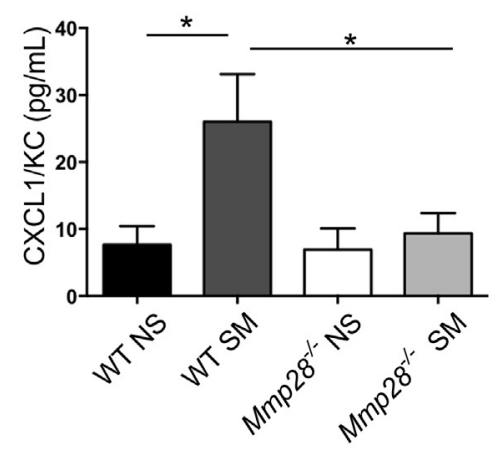

B

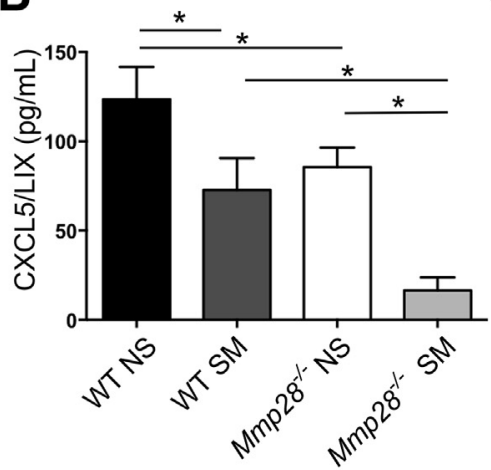

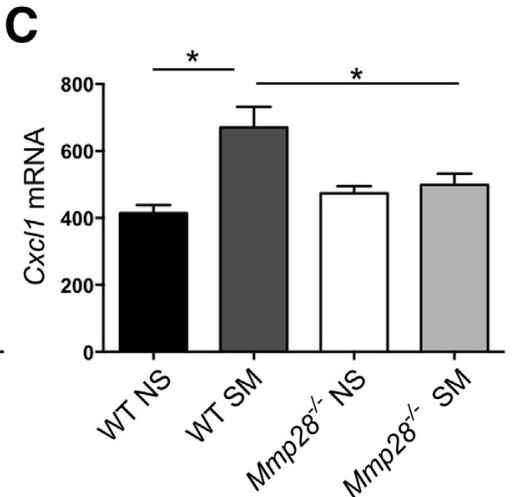

Figure 4 Altered chemokine gradients in $M m p 28^{-/-}$mice. After 3 to 6 months of smoke exposure, murine lungs were lavaged for assessment of chemokine levels. A: There is a modest increase in CXCL1/KC in smoke-exposed (SM) wild-type (WT) mice but not in smoke-exposed Mmp28 ${ }^{-/-}$mice. B: CXCL5/LIX is expressed in room air-exposed mice (NS), but significantly less so in $M m p 28^{-/-}$mice. After smoke exposure, CXCL5/LIX levels decrease in both genotypes. C: Cxcl1 mRNA was determined from Illumina beadchip arrays and values shown are intensity. $n=15$ per condition (B); $n=3$ to 5 per genotype per condition (C). ${ }^{*} P<0.05$. 

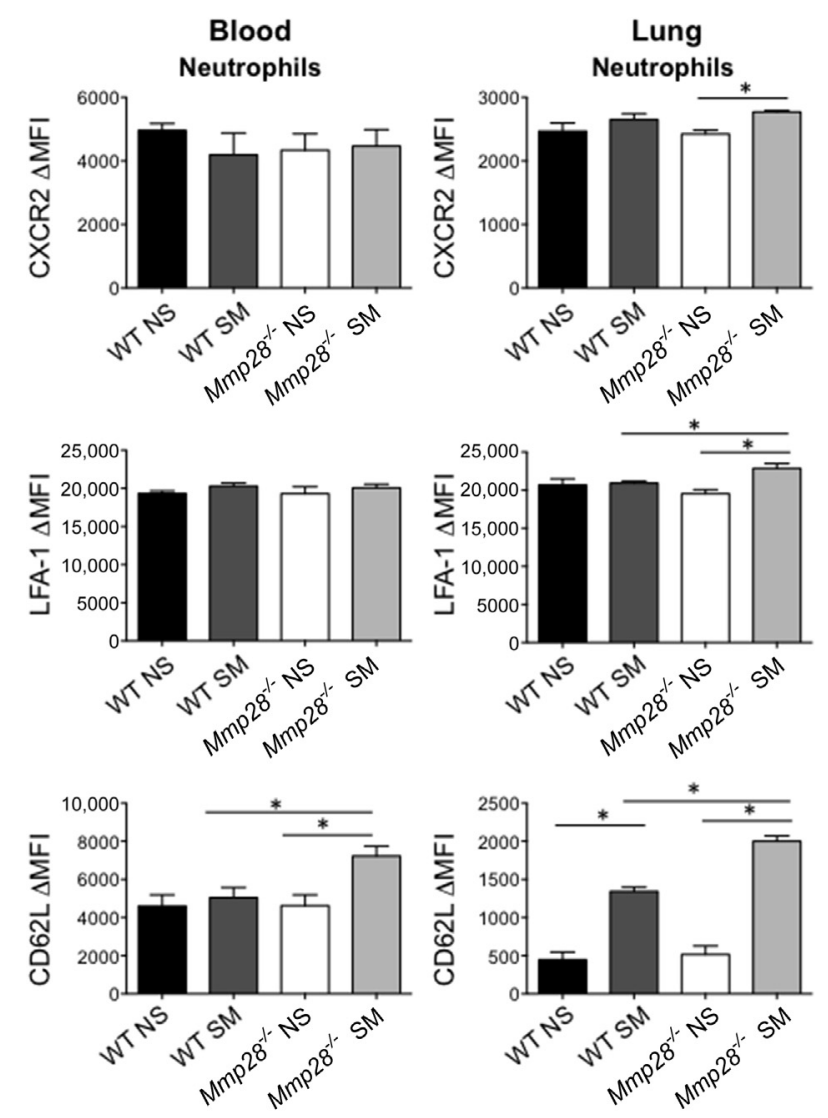

Figure 5 Chemokine and adhesion receptor expression on circulating monocytes and neutrophils. After 3 months of chronic tobacco smoke exposure (SM) or room air control (NS), wild-type (WT) and Mmp28-/blood and lung PMNs were collected for analysis of chemokine and adhesion receptor expression by FACS. On circulating PMNs from $M m p 28^{-/-}$SM mice, there is a significant increase in CD62L that is not seen in WT SM mice. In the lung compartment, smoke exposure significantly increases the expression of CD62L on PMNs in both genotypes. However, in $M m p 28^{-/-}$ $\mathrm{SM}$ mice, there are larger increases in $\mathrm{CD} 62 \mathrm{~L}$, lymphocyte function -associated antigen 1 (LFA-1), and CXCR2 expression on neutrophils compared to WT SM. ${ }^{*} P<0.05$. MFI, median fluorescent intensity.

destruction. In WT mice, 6 months of cigarette smoke exposure led to a significant decrease in alveolar tissue area and an increase in mean chord length, indicating the development of emphysema (Figure 1B). In contrast, $M m p 28^{-/-}$mice were protected from airspace destruction (Figure 1, B and C). These findings indicate that MMP-28 is necessary for development of emphysema, a previously unrecognized role of MMP-28.

\section{Neutrophil Recruitment into the Lung Is Dependent on Mmp28}

To determine whether MMP-28 regulates inflammatory changes at earlier time points, we performed a more detailed evaluation of leukocyte subsets in the blood, alveolar space, and lung compartments after 3 months of nearly daily cigarette smoke exposure. As expected, the average fold change (SM/NS) in alveolar macrophages was less in the 3-versus 6-month smoke-exposed WT mice (1.4- versus 2.1-fold, respectively), consistent with a progressive inflammatory response with prolonged exposure. Compared to NS mice, the alveolar macrophages in both SM genotypes were significantly larger and more granular as represented by their forward scatter and side scatter properties (Figure 2A), and there were similar increases in macrophage numbers in both smoke-exposed genotypes (Figure 2B), representing a majority of the bronchoalveolar cells.

In the lung compartment, we compared leukocyte populations as a percentage of $\mathrm{CD} 45^{+}$cells (Figure 2C). In smoke-exposed mice, the percentage alveolar macrophages increased similarly in both genotypes, and monocyte populations represented a smaller percentage of $\mathrm{CD} 45^{+}$cells in both smoke-exposed genotypes. However, there was a significant reduction in percentage PMNs in $M m p 28^{-/-} \mathrm{SM}$ versus WT SM mice. In addition, changes in B cells and $\mathrm{CD} 4{ }^{+} \mathrm{CD} 25^{+}$lymphocytes were seen in WT SM mice but not in $M m p 28^{-1-}$ SM mice compared to their respective room air-exposed controls. Hence, the leukocyte composition in the lung compartment of $M m p 28^{-/-}$SM resembled that of non-smoke-exposed mice.

We also evaluated PMN localization and quantification in WT and Mmp28 $8^{-/}$SM mouse lungs by immunohistochemistry (Figure 2, D and E). As suggested by FACS analysis, we observed fewer PMNs in Mmp2 $8^{-/-}$SM lungs and most of the PMNs appeared to be within or along the alveolar wall.

We also assessed leukocyte populations in the blood (Figure 3). Smoke exposure at 3 months significantly increased the percentage PMNs in WT mice but not in $M m p 28^{-/-}$mice. As in the lung compartment, changes in percentage B cells were seen only in WT SM mice but not in $M m p 28^{-/-} \mathrm{SM}$ mice as the $M m p 28^{-/}$SM leukocyte composition in the blood more closely resembled that of nonsmoked mice.

\section{Neutrophil Chemokines Are Reduced in $\mathrm{Mmp28}^{-/-}$ Mice}

Neutrophil recruitment requires a multistep process involving engagement of adhesion receptors and chemokine receptors with their ligands. Given reduced PMN recruitment in Mmp $28^{-/}$SM mice, we assessed the protein levels of neutrophil chemokines, CXCL1/KC, CXCL2/MIP2 $\alpha$, and CXCL5/LIX, in BAL fluid at 3 and 6 months of cigarette smoke or room air exposure (Figure 4). We found increased levels of CXCL1/KC in WT SM versus WT NS mice, but no change in $M m p 28^{-/-}$SM versus $M m p 28^{-/-}$NS mice. These findings suggest that MMP-28 contributes to CXCL1/KC expression in the lung (Figure 4A). CXCL2/MIP2 $\alpha$ was undetectable in all samples (data not shown), and we found constitutive expression of CXCL5/LIX in the BAL fluid from room air-exposed mice and reduced levels in smokeexposed mice with overall reduced expression in $M m p 28^{-/-}$ mice (Figure 4B). Although MMPs can contribute to CXCL1/KC gradients via proteolysis, ${ }^{43}$ we found that MMP28 regulated $\mathrm{CXCL} 1 / \mathrm{KC}$ at the transcriptional level, as we 

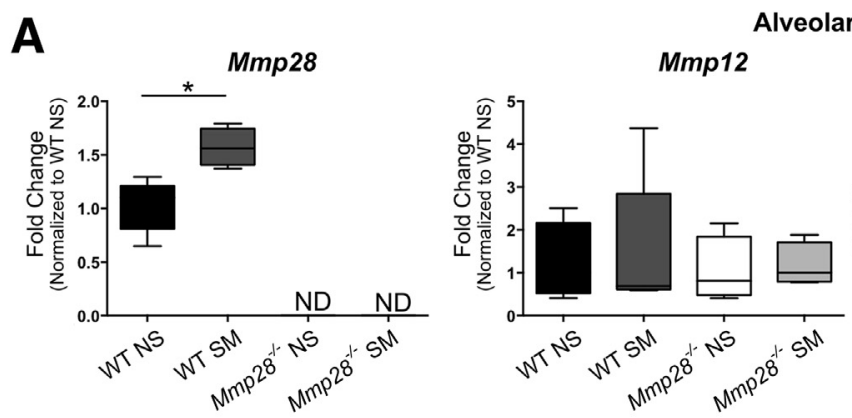

B

Lung
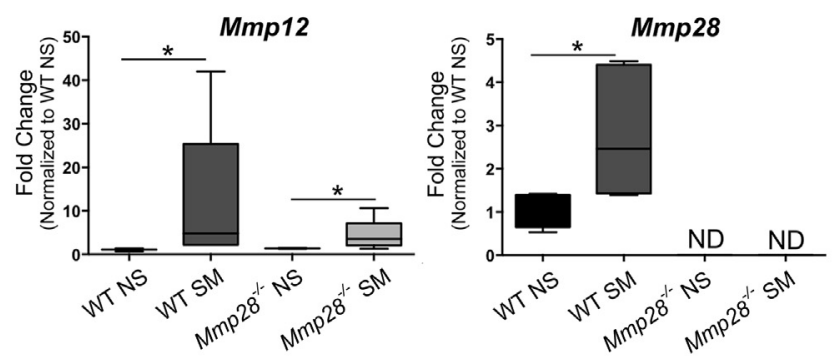

observed reduced gene expression in $M m p 28^{-/-}$SM lungs compared to WT SM lungs (Figure 4C).

We also assessed the surface expression of adhesion and chemokine receptors on PMNs isolated from the blood and lung (Figure 5). In the lung compartment, smoke exposure increased intercellular adhesion molecule 1 (data not shown) and CD62L expression on neutrophils (Figure 5). However, the absence of Mmp28 was associated with greater expression of CD62L on neutrophils isolated from blood and lung in smoke-exposed mice. In addition to CD62L, there was greater expression of lymphocyte function-associated antigen 1 in smoke-exposed $M m p 28^{-/-}$neutrophils compared to WT cells, suggestive of more global changes in neutrophil phenotypes in the absence of Mmp28. Hence, the absence of MMP-28 is associated with several perturbations in neutrophil adhesion receptors and chemokines that may contribute to or be a consequence of reduced neutrophil recruitment to chronic cigarette smoke exposure.

We assessed if Mmp 28 altered other PMN phenotypes. We tested WT and $M m p 28^{--}$PMNs for myeloperoxidase and neutrophil elastase levels at baseline and after stimulation with phorbol myristate acetate. We found a similar ability of WT and Mmp $28^{-1-}$ PMNs to respond to phorbol myristate acetate, as measured by release of myeloperoxidase and total neutrophil elastase in cell lysates. These data indicate that there are no innate functional abnormalities in neutrophils from $M m p 28^{-/-}$mice (Supplemental Figure S1).

\section{Altered Gene Expression by Mmp28 ${ }^{-/-}$Pulmonary Macrophages}

Given the established importance of macrophages in emphysema pathogenesis, we were surprised by the initial

\section{Mmp9}
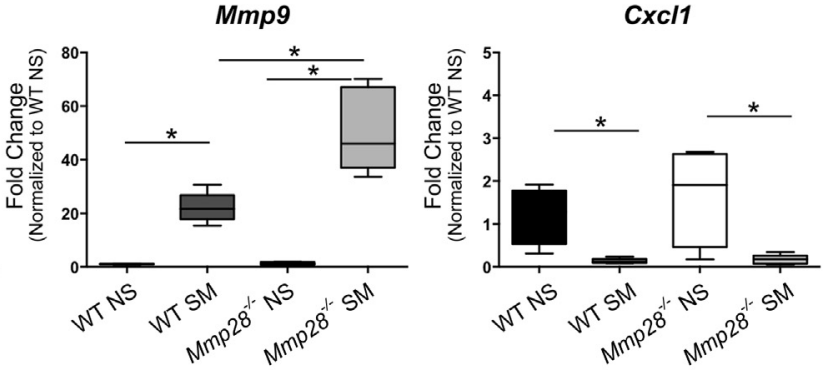

Figure 6 Smoke-induced and Mmp28-associated changes in macrophage activation. After 3 months of smoke exposure or room air control, alveolar macrophages from wild-type (WT) and $M m p 28^{-/-}$mice were sorted and assessed for Mmp-9, Mmp-12, Mmp-28, and Cxcl1 mRNA expression (A) and whole lung RNA was assessed for Mmp-12 and Mmp28 expression (B). A: Smoke exposure increases expression of Mmp-9 and Mmp-28 but not Mmp-12. The absence of Mmp-28 is associated with a significant increase in Mmp-9 expression, and smoke exposure is associated with a decrease in Cxcl1 expression across genotypes. B: Smoke exposure increases both $\mathrm{Mmp}-12$ and $\mathrm{Mmp}-28$ in the whole lung. ${ }^{*} P<0.05$. ND, not detected; NS, room air control; SM, chronic tobacco smoke exposure.

increase in macrophage numbers in $M m p 28^{-/-}$SM mice but blunting of other leukocyte changes. Because we previously showed that Mmp28 also drives macrophage activation states, dampening M1 and promoting M2 gene expression, ${ }^{35}$ we hypothesized that altered macrophage polarization may change expression of other genes, such as Mmps or chemokines, contributing to reduced leukocyte recruitment or extracellular matrix degradation. We sorted alveolar macrophages by gating on $\mathrm{CD}^{+} 5^{+}$(white blood) cells and excluding $\mathrm{Ly}_{6 \mathrm{G}}^{+}$cells (PMNs). Alveolar macrophages were identified as $\mathrm{CD} 11 \mathrm{c}^{+} \mathrm{SigF}^{+} \mathrm{CD} 11 \mathrm{~b}^{\text {low }}$ cells, and these cells were also high forward scatter and side scatter, as shown (Figure 2A). In other models of lung injury, $\mathrm{CD} 11 \mathrm{~b}^{\text {high }}$ expression can distinguish recruited from resident alveolar macrophages; however, we found that most high forward scatter/side scatter cells expressed markers of resident alveolar macrophages (data not shown). Sorted cells were processed for RNA isolation to determine gene expression of $M m p 9,12,28$, and Cxcll.

We found that smoke exposure increased alveolar macrophage expression of $\mathrm{Mmp} 9$ and 28 (Figure 6A). In the absence of Mmp28, alveolar macrophages had greater smoke-related increases in $M m p 9$ expression. Surprisingly, we did not observe a change in macrophage expression of Mmp12 by exposure or genotype (Figure 6A). However, in total lung RNA, we observed an increase in Mmpl2 expression in smoke-exposed WT and $\mathrm{Mmp} 28^{-/-}$mice compared to NS controls, likely reflecting the increased numbers of macrophages recruited to the lung at this early time point (Figure 6B).

Next, we asked whether alveolar macrophages may be the source of the altered expression of neutrophil chemokine, Cxcll. In contrast to what we observed in the whole lung 


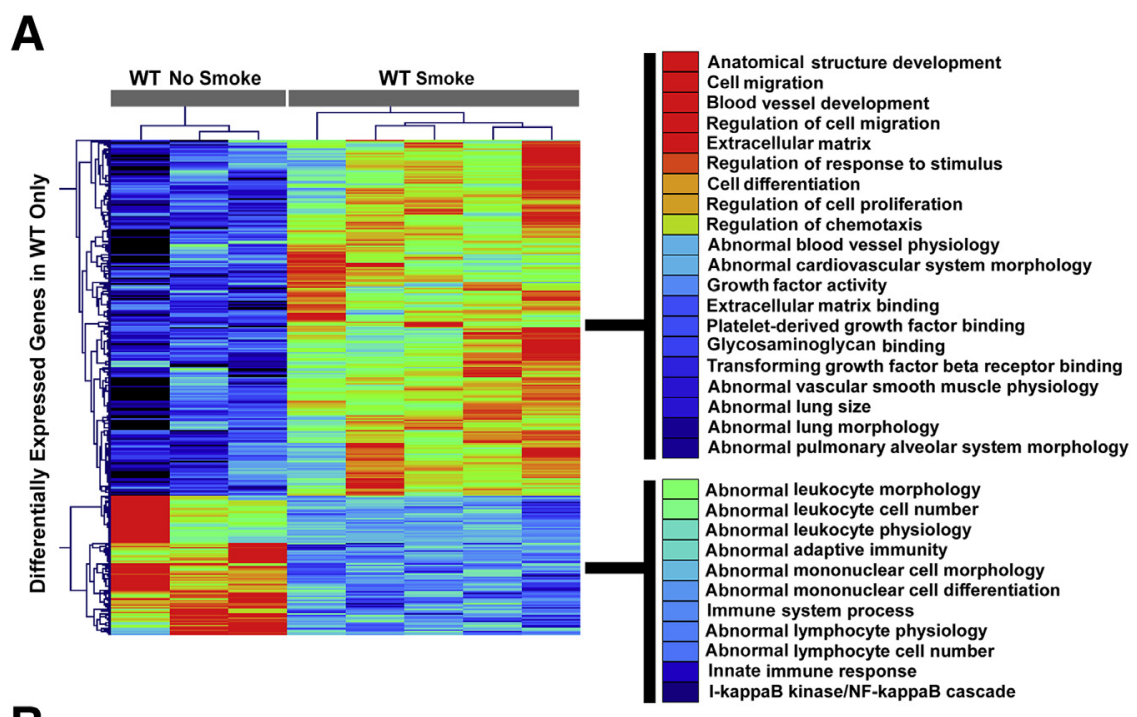

B

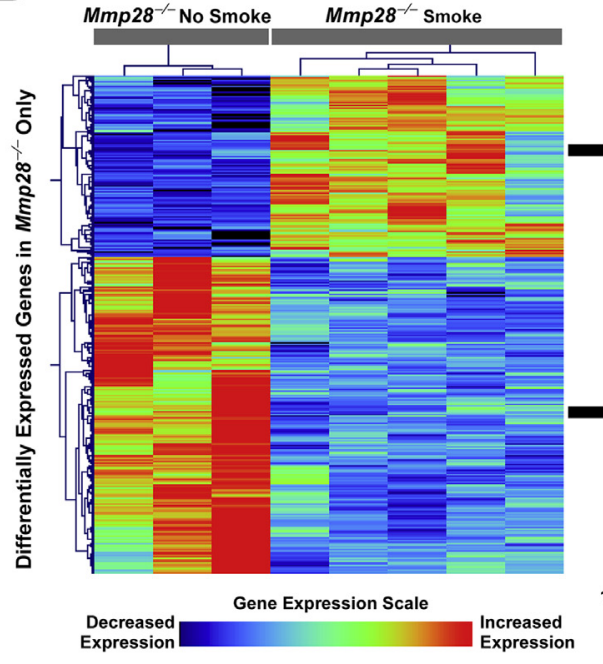

Figure 7 Whole-lung transcriptomic analysis reveals a distinct role for Mmp28 in promoting immunoinflammatory and remodeling programs. Chronic (3-month) exposure to cigarette smoke induces common and divergent gene expression patterns in wild-type (WT) and Mmp28 ${ }^{-/-}$mice, but using a step-wise statistical approach, we focused on genotype-specific transcriptional responses to smoke exposure. A: Genes selectively differentially expressed only in smoke-exposed WT animals are enriched in pathways involved in extracellular matrix remodeling, development, abnormal lung morphology, as well as dysregulated immune and inflammatory responses. B: In contrast, functional enrichment of genes selectively differentially expressed in $\mathrm{Mmp} 28^{-/-}$mice is much more modest and involves mitochondrial, metabolic, and binding processes.
(Figure 4C), we found that Cxcll was not differentially expressed by $M m p 28^{-/-}$macrophages compared to WT cells. In fact, its gene expression was lower in smoked versus nonsmoked conditions independent of genotype (Figure 6). Overall, these data suggest that $M m p 28$ regulates the activation state of the macrophage, but the alveolar macrophage is not directly contributing to altered gene expression of the neutrophil chemokine $\mathrm{Cxcl}$. Hence, $\mathrm{Mmp} 28$ may be altering chemokine expression by other cell populations.

\section{Transcriptional Analysis in Cigarette Smoke-Exposed} Mice Reveals a Distinct Role for Mmp28 in Promoting Immunoinflammatory and Remodeling Responses in Lung

To obtain an overview of Mmp28's role in transcriptional regulation during chronic tobacco smoke exposure, we performed microarray analysis on nonsmoked and 3-month-smoked WT and Mmp2 $8^{-/-}$murine lungs using whole-genome Illumina Beadchips. We identified approximately 1800 differentially expressed transcripts in smoked versus nonsmoked WT mice, and 1900 differentially expressed transcripts in smoked versus nonsmoked Mmp $28^{-/-}$mice using an FDR $<0.01$ (corresponding $P$ value $<0.0007)$. More than 1000 of these transcripts were common between the two genotypes, indicating significant overlap between WT and $M m p 28^{-/-}$transcriptional responses to cigarette smoke exposure. Because we were particularly interested in genes whose expression profiles were selectively altered in a genotype-specific pattern, we focused on subsets of genes that were differentially expressed in one genotype (at FDR $<0.01$ ), but not the other (ie, at FDR $>0.1$ ). We identified 338 transcripts exclusively differentially expressed in WT mice exposed to 3 months of tobacco smoke (243 up-regulated, 95 downregulated), and 340 transcripts exclusively differentially expressed in smoke-exposed $\mathrm{Mmp}^{-8^{-/}}$animals (124 upregulated, 216 down-regulated). Functional enrichment analysis of these genotype-specific differentially expressed genes revealed that in WT mice processes involved in extracellular remodeling, development, cell migration, and proliferation were up-regulated, whereas immune and inflammatory processes were generally down-regulated 


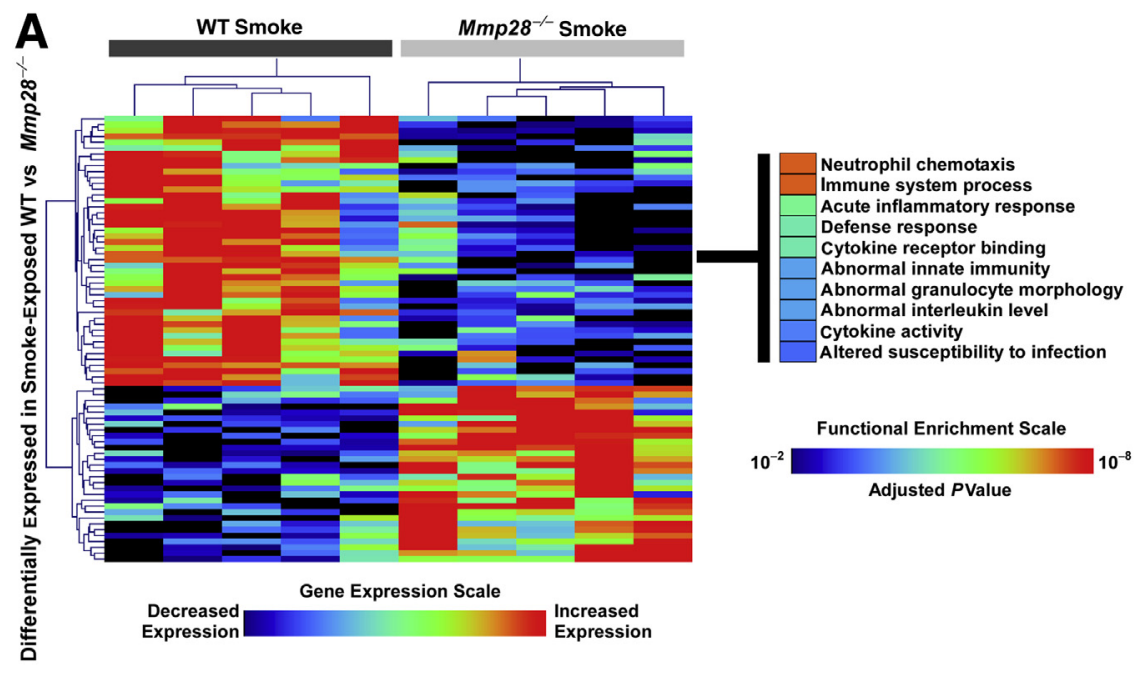

B

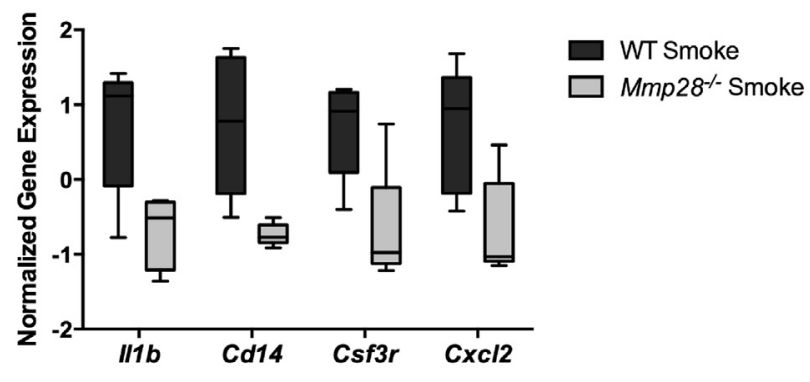

Figure 8 Chronic smoke exposure induces selective differential gene expression profiles in

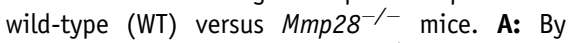
directly comparing WT and Mmp28 ${ }^{-/-}$mice exposed to cigarette smoke, we identified a limited set of genes that are up-regulated in WT relative to $\mathrm{Mmp}^{28^{-/-}}$and mapped to neutrophil chemotaxis, immune and defense response, and cytokine activity. B: Box-and-whisker plot showing increased expression levels of four representative genes (Il1b, Cd14, Csf3, Cxcl2) in smoke-exposed WT mice.
(Figure 7A). In contrast, none of these transcriptional programs were enriched among genes exclusively differentially expressed in Mmp2 $8^{-/-}$mice (Figure 7B). Taken together, our unbiased transcriptional analysis suggests that $\mathrm{Mmp} 28$ is associated with differential expression of a subset of genes intimately involved in tissue remodeling and dysregulated immunity in cigarette smoke-exposed lung.

To query other pathways regulated by Mmp28 that may have been excluded by our initial approach, we directly compared gene expression changes between smoke-exposed WT versus $M m p 28^{-1-}$ mice. We found a modest number of differentially expressed genes between the genotypes and used a more permissive $P$ value $<0.001$ threshold to explore genotype-specific transcriptional responses after chronic smoke exposure. We identified 76 differentially expressed transcripts, of which 46 were increased in WT relative to $\mathrm{Mmp} 28^{-/-}$and 30 were increased in $\mathrm{Mmp} 28^{-/-}$ relative to WT mice (Figure 8A). Functional analysis of these genotype-specific differentially expressed genes revealed that processes involved in immunity, leukocyte chemotaxis, and cytokine activity were enriched in smokeexposed WT mice, whereas transcripts up-regulated in $M m p 28^{-/-}$mice were not significantly enriched in any functional category (based on an adjusted enrichment $P$ value cutoff $<0.01)$. Representative genes with higher expression in smoke-exposed WT versus $\mathrm{Mmp} 28^{-/-}$mice that mapped to cytokine/chemokine signaling included those involved in inflammation and PMN recruitment, such as Illb, Csf3, Cxcll, and Cxcl2 (Figures 4C and 8B). Consistent with our observed changes in leukocyte populations to smoke exposure, these results support our findings that Mmp28's main function in chronic tobacco smoke exposure is to modulate immunoinflammatory gene expression and indicate that the differences observed in the CXCL1/KC protein levels are, at least in part, transcriptionally regulated.

\section{MMP-28 Expression Increases in Lung and Macrophage Compartments in Human COPD}

Given our findings of a significant contributory role for Mmp28 in murine emphysema pathogenesis, we evaluated the expression of human MMP-28 in the lungs from those without pulmonary disease (non-COPD) and those with COPD. We obtained eight to nine samples from each group and evaluated the lung tissue for MMP-28 expression by immunohistochemistry. In healthy controls, we found the predominant expression of MMP-28 within the bronchoepithelium and alveolar macrophage (Figure 9, A-D and I). In COPD samples, we observed an increase of MMP-28 within alveolar tissue and alveolar macrophages (Figure 9, E-H and $\mathrm{K})$. As we observed in the control samples, the bronchoepithelium continued to highly express MMP-28 with increased extracellular staining in COPD samples (Figure 9, $\mathrm{H}$ and J). 


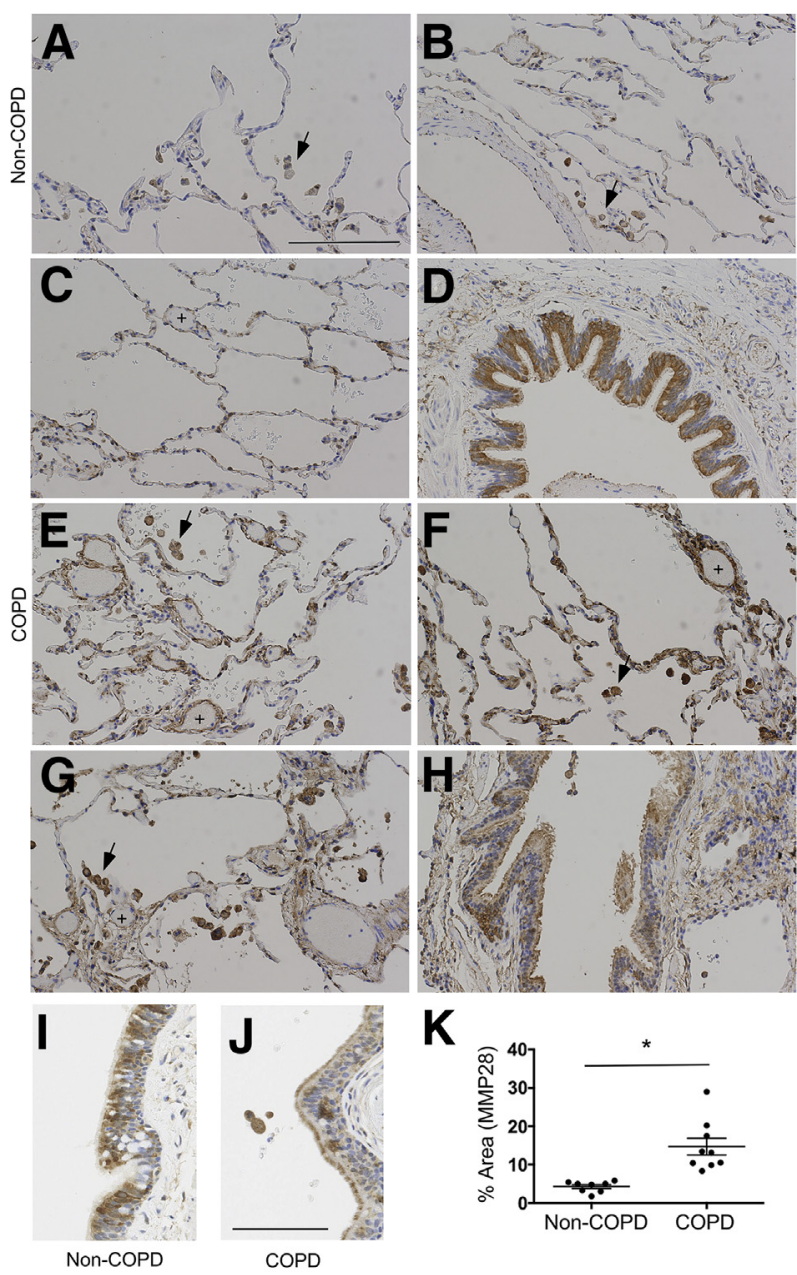

Figure 9 Matrix metalloproteinase-28 (MMP-28) is highly expressed in COPD lungs. Lung tissue sections were obtained from eight non-COPD and nine COPD deidentified samples. Lung slices were stained with an antihuman MMP-28 antibody or isotype control. A-D: In the non-COPD samples, alveolar macrophages (arrows) express MMP-28, and the bronchoepithelium (D and I) most highly expresses MMP-28. E-H: In COPD samples, the alveolar macrophages (arrows) highly express MMP-28, and there is increased expression within the alveolar tissue and post-capillary venules (plus signs). The bronchoepithelium $(\mathbf{H})$ also highly expresses MMP-28 with increased expression in the mucociliary layer along the apical surface of the cells (J). K: Quantification of MMP-28 in lung tissue (excluding airways) demonstrated increased percentage area in COPD tissue. ${ }^{*} P<0.05$. Scale bars: $200 \mu \mathrm{m}(\mathbf{A}-\mathbf{H}) ; 100 \mu \mathrm{m}$ (I and $\left.\mathbf{J}\right)$.

Interestingly, in all COPD samples, we also observed prominent MMP-28 expression along pulmonary venules, a finding that was not observed in non-COPD lung tissue.

\section{Discussion}

It is well recognized that MMPs not only have roles in matrix biology but also in regulating inflammatory cell recruitment via pleiotropic effects on chemokine and cytokine biology and their gradients, as well as via other processes. ${ }^{44}$ Chronic inflammation in response to cigarette smoke exposure, in particular macrophage recruitment, is an important driver of emphysema. ${ }^{45}$ Macrophages are activated by cigarette smoke and secrete inflammatory proteins that orchestrate recruitment of neutrophils and lymphocytes that together elaborate elastolytic enzymes that contribute to lung destruction. Neutrophils contribute to emphysema by releasing proteinases, such as neutrophil elastase, reactive oxygen species, and other proinflammatory mediators, that work in concert with macrophage elastase. ${ }^{46}$

Our findings highlight a novel and unexpected role for MMP-28 in mediating the inflammatory response to chronic tobacco smoke exposure. An early phenotype appears to be a global reduction in PMN recruitment into the lungs. These changes were also recapitulated in the vascular compartment, suggesting that neutrophil recruitment into the blood is MMP-28 dependent. Although neutrophils make up a small component of the inflammatory cells in this model, mice deficient in neutrophil elastase are significantly protected from emphysema. ${ }^{46}$ Hence, these differences may have important consequences in protecting $\mathrm{Mmp} 28^{-1-}$ mice from cigarette smoke-induced emphysema.

Because PMN recruitment is dependent on their adhesion receptor expression, we hypothesized that $\mathrm{Mmp} 28$ may be regulating their expression on leukocytes. In fact, we found increased CD62L and lymphocyte function-associated antigen 1 expression by PMNs from $M m p 28^{-/}$SM mice versus WT SM cells. One explanation for increased CD62L on the surface of PMNs from Mmp2 $28^{-/-}$mice is loss of MMP-28-dependent shedding of CD62L. Although a disintegrin and metalloproteinase 17 is the predominant sheddase for CD62L, others have shown another MMP to be involved in CD62L shedding in apoptotic PMNs. ${ }^{47} \mathrm{We}$ evaluated apoptotic PMNs in a thioglycollate peritonitis model and found no MMP-28-dependent roles in CD62L shedding (data not shown), suggesting that these changes in CD62L are downstream of MMP-28 activity. We also assessed if MMP-28 altered other PMN phenotypes and found a similar ability of WT and $M m p 28^{-/-}$PMNs to respond to phorbol myristate acetate, as measured by myeloperoxidase and neutrophil elastase activity. Hence, these findings of altered CD62L expression among other receptors are suggestive that MMP-28 alters neutrophil activation states via changing the environmental milieu, and it may do so via alteration of chemotactic signals.

Neutrophil recruitment is dependent on generation of chemokine gradients, and we assessed CXC chemokine levels in the BAL. Most BAL chemokine levels at the 3-and 6-month time points were minimal; however, we observed a small increase in CXCL1/KC in smoke-exposed WT mice but not that of smoke-exposed $M m p 28^{-/-}$mice. Similarly, there was increased CXCL1/KC gene transcription in smoke-exposed WT lungs, and this increase was not seen in Mmp $28^{-1-}$ tissue. Therefore, the changes on the protein level were because of transcriptional changes and not directly related to MMP-28-mediated proteolysis causing altered chemokine gradients, as has been reported for other MMPs. ${ }^{44}$ However, the cellular source for reduced CXCL1/ 
KC expression was not because of differential expression of CXCL1/KC by the macrophage, suggesting other cell sources, such as the epithelium.

As in our other studies, we found that monocytes express MMP-28 at high levels (data not shown). We also found that resident alveolar macrophages express MMP-28 and upregulate MMP-28 expression in response to cigarette smoke. The absence of MMP-28 was associated with greater smokeinduced increases of MMP-9. However, these findings do not explain the protective effect we observed in $M m p 28^{-/-}$mice, as others have shown that MMP-9 has no contributory role in cigarette smoke-induced emphysema in mice. ${ }^{48}$ Rather, this change likely reflects altered macrophage phenotypes, consistent with our previous findings of MMP-28 as a regulator of macrophage activation. ${ }^{35}$ Although the role of macrophage activation in COPD pathogenesis is complex, greater M2 polarization has been associated with COPD, and we and others have found that M2 cells up-regulate Mmp12, the predominant MMP contributing to emphysema pathogenesis in mice. ${ }^{25,49,50}$ Although we found reduced expression

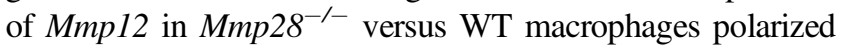
with IL-4 in vitro (data not shown), we did not observe differences in Mmpl2 or Cxcll in the sorted pulmonary macrophages based on genotype. Hence, there are likely other pathways and cell sources by which MMP-28 mediates emphysema pathogenesis. In fact, the global gene expression from lung suggests differential activation of wound repair responses and inflammatory pathways seen in WT but not Mmp $28^{-/-}$mice.

MMP-28 is expressed by several cell sources, including the lung epithelium (Club cells) and leukocytes-hence, future studies will be needed to help dissect the contribution of these cellular sources of MMP-28. In this study, we are the first to demonstrate MMP-28 expression in human lung tissue from those without lung disease and those with COPD. We found that MMP-28 is highly expressed by the bronchoepithelium in both conditions. Interestingly, we also observed increased extracellular staining along the cilia in COPD samples, and this finding could represent secreted MMP-28 bound to extracellular or cell membrane proteins. We also observed increased MMP-28 expression in the alveolar compartment and in macrophages in COPD samples. Although all COPD samples were from former smokers, we do not know if it is smoke exposure or COPD that drives MMP-28 up-regulation in the lung, and additional studies from active smokers without COPD are needed to address this question. Unfortunately, we could not find a working antibody to examine MMP-28 localization in murine tissue, but we found increased Mmp28 transcription in sorted macrophages and whole lung from mice exposed to chronic tobacco smoke. Although we do not know MMP-28's contribution to human disease, our data in murine emphysema suggest contributory roles in disease pathogenesis.

Our data demonstrate a novel role for MMP-28 in promoting chronic lung inflammation and tissue remodeling induced by cigarette smoke and highlight another potential target to modulate emphysema. Future studies are required to identify the cell source and protein target(s) responsible for these phenotypes.

\section{Supplemental Data}

Supplemental material for this article can be found at http://dx.doi.org/10.1016/j.ajpath.2017.02.008.

\section{References}

1. Senior RM, Anthonisen NR: Chronic obstructive pulmonary disease (COPD). Am J Respir Crit Care Med 1998, 157:S139-S147

2. Barnes PJ, Shapiro SD, Pauwels RA: Chronic obstructive pulmonary disease: molecular and cellular mechanisms. Eur Respir J 2003, 22 672-688

3. Shapiro SD: Proteinases in chronic obstructive pulmonary disease. Biochem Soc Trans 2002, 30:98-102

4. Cardoso WV, Sekhon HS, Hyde DM, Thurlbeck WM: Collagen and elastin in human pulmonary emphysema. Am Rev Respir Dis 1993, 147:975-981

5. Dillon TJ, Walsh RL, Scicchitano R, Eckert B, Cleary EG, McLennan G: Plasma elastin-derived peptide levels in normal adults, children, and emphysematous subjects: physiologic and computed tomographic scan correlates. Am Rev Respir Dis 1992, 146: $1143-1148$

6. Vlahovic G, Russell ML, Mercer RR, Crapo JD: Cellular and connective tissue changes in alveolar septal walls in emphysema. Am J Respir Crit Care Med 1999, 160:2086-2092

7. Hogg JC, Senior RM: Chronic obstructive pulmonary disease, part 2: pathology and biochemistry of emphysema. Thorax 2002, 57: $830-834$

8. Tetley TD: Macrophages and the pathogenesis of COPD. Chest 2002, $121: 156 \mathrm{~S}-159 \mathrm{~S}$

9. Russell RE, Thorley A, Culpitt SV, Dodd S, Donnelly LE, Demattos C, Fitzgerald M, Barnes PJ: Alveolar macrophage-mediated elastolysis: roles of matrix metalloproteinases, cysteine, and serine proteases. Am J Physiol Lung Cell Mol Physiol 2002, 283: L867-L873

10. Shapiro SD: Elastolytic metalloproteinases produced by human mononuclear phagocytes: potential roles in destructive lung disease. Am J Respir Crit Care Med 1994, 150:S160-S164

11. Foronjy R, D'Armiento J: The role of collagenase in emphysema. Respir Res 2001, 2:348-352

12. Betsuyaku T, Nishimura M, Takeyabu K, Tanino M, Venge P, Xu S, Kawakami Y: Neutrophil granule proteins in bronchoalveolar lavage fluid from subjects with subclinical emphysema. Am J Respir Crit Care Med 1999, 159:1985-1991

13. Zheng $\mathrm{T}$, Zhu Z, Wang Z, Homer RJ, Ma B, Riese RJ Jr, Chapman HA Jr, Shapiro SD, Elias JA: Inducible targeting of IL-13 to the adult lung causes matrix metalloproteinase- and cathepsindependent emphysema. J Clin Invest 2000, 106:1081-1093

14. Belvisi MG, Bottomley KM: The role of matrix metalloproteinases (MMPs) in the pathophysiology of chronic obstructive pulmonary disease (COPD): a therapeutic role for inhibitors of MMPs? Inflamm Res 2003, 52:95-100

15. Cataldo DD, Gueders MM, Rocks N, Sounni NE, Evrard B, Bartsch P, Louis R, Noel A, Foidart JM: Pathogenic role of matrix metalloproteases and their inhibitors in asthma and chronic obstructive pulmonary disease and therapeutic relevance of matrix metalloproteases inhibitors. Cell Mol Biol (Noisy-le-grand) 2003, 49:875-884

16. Selman M, Cisneros-Lira J, Gaxiola M, Ramirez R, Kudlacz EM, Mitchell PG, Pardo A: Matrix metalloproteinases inhibition attenuates 
tobacco smoke-induced emphysema in guinea pigs. Chest 2003, 123 $1633-1641$

17. Churg A, Wright JL: Proteases and emphysema. Curr Opin Pulm Med 2005, 11:153-159

18. Demedts IK, Morel-Montero A, Lebecque S, Pacheco Y, Cataldo D, Joos GF, Pauwels RA, Brusselle GG: Elevated MMP-12 protein levels in induced sputum from patients with COPD. Thorax 2006, 61:196-201

19. Hunninghake GM, Cho MH, Tesfaigzi Y, Soto-Quiros ME, Avila L, Lasky-Su J, Stidley C, Melén E, Söderhäll C, Hallberg J, Kull I, Kere J, Svartengren M, Pershagen G, Wickman M, Lange C, Demeo DL, Hersh CP, Klanderman BJ, Raby BA, Sparrow D, Shapiro SD, Silverman EK, Litonjua AA, Weiss ST, Celedón JC: MMP12, lung function, and COPD in high-risk populations. N Engl J Med 2009, 361:2599-2608

20. Foronjy R, Nkyimbeng T, Wallace A, Thankachen J, Okada Y, Lemaitre V, D'Armiento J: Transgenic expression of matrix metalloproteinase- 9 causes adult-onset emphysema in mice associated with the loss of alveolar elastin. Am J Physiol Lung Cell Mol Physiol 2008, 294:L1149-L1157

21. Gharib SA, Loth DW, Soler Artigas M, Birkland TP, Wilk JB, Wain LV, CHARGE Consortium, SpiroMeta Consortium, et al: Integrative pathway genomics of lung function and airflow obstruction. Hum Mol Genet 2015, 24:6836-6848

22. Glasser SW, Detmer EA, Ikegami M, Na CL, Stahlman MT, Whitsett JA: Pneumonitis and emphysema in sp-C gene targeted mice. J Biol Chem 2003, 278:14291-14298

23. Wert SE, Yoshida M, LeVine AM, Ikegami M, Jones T, Ross GF, Fisher JH, Korfhagen TR, Whitsett JA: Increased metalloproteinase activity, oxidant production, and emphysema in surfactant protein D gene-inactivated mice. Proc Natl Acad Sci U S A 2000, 97: $5972-5977$

24. Wang Z, Zheng T, Zhu Z, Homer RJ, Riese RJ, Chapman HA Jr, Shapiro SD, Elias JA: Interferon gamma induction of pulmonary emphysema in the adult murine lung. J Exp Med 2000, 192:1587-1600

25. Hautamaki RD, Kobayashi DK, Senior RM, Shapiro SD: Requirement for macrophage elastase for cigarette smoke-induced emphysema in mice. Science 1997, 277:2002-2004

26. Kassim SY, Fu X, Liles WC, Shapiro SD, Parks WC, Heinecke JW: $\mathrm{NADPH}$ oxidase restrains the matrix metalloproteinase activity of macrophages. J Biol Chem 2005, 280:30201-30205

27. Owen CA, Hu Z, Barrick B, Shapiro SD: Inducible expression of tissue inhibitor of metalloproteinases: resistant matrix metalloproteinase-9 on the cell surface of neutrophils. Am J Respir Cell Mol Biol 2003, 29:283-294

28. Owen CA, Hu Z, Lopez-Otin C, Shapiro SD: Membrane-bound matrix metalloproteinase- 8 on activated polymorphonuclear cells is a potent, tissue inhibitor of metalloproteinase-resistant collagenase and serpinase. J Immunol 2004, 172:7791-7803

29. Illman SA, Keski-Oja J, Parks WC, Lohi J: The mouse matrix metalloproteinase, epilysin (MMP-28), is alternatively spliced and processed by a furin-like proprotein convertase. Biochem J 2003, 375:191-197

30. Illman SA, Keski-Oja J, Lohi J: Promoter characterization of the human and mouse epilysin (MMP-28) genes. Gene 2001, 275:185-194

31. Lohi J, Wilson CL, Roby JD, Parks WC: Epilysin, a novel human matrix metalloproteinase (MMP-28) expressed in testis and keratinocytes and in response to injury. J Biol Chem 2001, 276:10134-10144

32. Manicone AM, Harju-Baker S, Johnston LK, Chen AJ, Parks WC: Epilysin (matrix metalloproteinase-28) contributes to airway epithelial cell survival. Respir Res 2011, 12:144
33. Illman SA, Lehti K, Keski-Oja J, Lohi J: Epilysin (MMP-28) induces TGF-beta mediated epithelial to mesenchymal transition in lung carcinoma cells. J Cell Sci 2006, 119:3856-3865

34. Ma Y, Halade GV, Zhang J, Ramirez TA, Levin D, Voorhees A, Jin YF, Han HC, Manicone AM, Lindsey ML: Matrix metalloproteinase-28 deletion exacerbates cardiac dysfunction and rupture after myocardial infarction in mice by inhibiting $\mathrm{m} 2$ macrophage activation. Circ Res 2013, 112:675-688

35. Gharib SA, Johnston LK, Huizar I, Birkland TP, Hanson J, Wang Y, Parks WC, Manicone AM: MMP28 promotes macrophage polarization toward M2 cells and augments pulmonary fibrosis. J Leukoc Biol 2014, 95:9-18

36. Manicone AM, Birkland TP, Lin M, Betsuyaku T, van Rooijen N, Lohi J, Keski-Oja J, Wang Y, Skerrett SJ, Parks WC: Epilysin (MMP-28) restrains early macrophage recruitment in Pseudomonas aeruginosa pneumonia. J Immunol 2009, 182:3866-3876

37. Houghton AM, Quintero PA, Perkins DL, Kobayashi DK, Kelley DG, Marconcini LA, Mecham RP, Senior RM, Shapiro SD: Elastin fragments drive disease progression in a murine model of emphysema. J Clin Invest 2006, 116:753-759

38. Kayala MA, Baldi P: Cyber-T web server: differential analysis of high-throughput data. Nucleic Acids Res 2012, 40:W553-W559

39. Benjamini Y, Hochberg Y: Controlling the false discovery rate: a practical and powerful approach to multiple testing. J R Stat Soc Ser B Methodological 1995, 57:289-300

40. Wang J, Duncan D, Shi Z, Zhang B: WEB-based GEne SeT AnaLysis Toolkit (WebGestalt): update 2013. Nucleic Acids Res 2013, 41:W77-W83

41. Gene Ontology Consortium: Gene Ontology Consortium: going forward. Nucleic Acids Res 2015, 43:D1049-D1056

42. Smith CL, Goldsmith CA, Eppig JT: The mammalian phenotype ontology as a tool for annotating, analyzing and comparing phenotypic information. Genome Biol 2005, 6:R7

43. Li Q, Park PW, Wilson CL, Parks WC: Matrilysin shedding of syndecan-1 regulates chemokine mobilization and transepithelial efflux of neutrophils in acute lung injury. Cell 2002, 111:635-646

44. Manicone AM, McGuire JK: Matrix metalloproteinases as modulators of inflammation. Semin Cell Dev Biol 2008, 19:34-41

45. Barnes PJ: Mediators of chronic obstructive pulmonary disease. Pharmacol Rev 2004, 56:515-548

46. Shapiro SD, Goldstein NM, Houghton AM, Kobayashi DK, Kelley D, Belaaouaj A: Neutrophil elastase contributes to cigarette smoke-induced emphysema in mice. Am J Pathol 2003, 163: 2329-2335

47. Li Y, Brazzell J, Herrera A, Walcheck B: ADAM17 deficiency by mature neutrophils has differential effects on L-selectin shedding. Blood 2006, 108:2275-2279

48. Atkinson JJ, Lutey BA, Suzuki Y, Toennies HM, Kelley DG, Kobayashi DK, Ijem WG, Deslee G, Moore CH, Jacobs ME, Conradi SH, Gierada DS, Pierce RA, Betsuyaku T, Senior RM: The role of matrix metalloproteinase- 9 in cigarette smoke-induced emphysema. Am J Respir Crit Care Med 2011, 183:876-884

49. Gratchev A, Kzhyshkowska J, Utikal J, Goerdt S: Interleukin-4 and dexamethasone counterregulate extracellular matrix remodelling and phagocytosis in type-2 macrophages. Scand J Immunol 2005, 61: $10-17$

50. Shaykhiev R, Krause A, Salit J, Strulovici-Barel Y, Harvey BG, O'Connor TP, Crystal RG: Smoking-dependent reprogramming of alveolar macrophage polarization: implication for pathogenesis of chronic obstructive pulmonary disease. J Immunol 2009, 183:2867-2883 